\title{
Validity of Lithuanian Version of the Child Perceptions Questionnaire Among Adolescents up to the Ages of 18
}

\author{
Aistė Kavaliauskienè ${ }^{1 *}$, Antanas Šidlauskas ${ }^{1}$ and Apolinaras Zaborskis ${ }^{2}$ \\ ${ }^{1 *}$ Department of Orthodontics, Faculty of Odontology, Medical Academy, Lithuanian University of Health Sciences, Kaunas, Lithuania \\ ${ }^{2}$ Department of Preventive Medicine \& Health Research Institute, Faculty of Public Health, Medical Academy, Lithuanian University of Health \\ Sciences, Kaunas, Lithuania
}

*Correspondence to: Aistė Kavaliauskienè, Department of Orthodontics, Faculty of Odontology, Medical Academy, Lithuanian University of Health Sciences, J.LukšosDaumanto Str. 6, LT-50106 Kaunas, Lithuania; Email: aiste.kavaliauskiene@lsmuni.lt.

Received: April 11, 2018; Accepted: April 24, 2018; Published: April 26, 2018;

\begin{abstract}
Background: The Child Perceptions Questionnaire (CPQ) is the most commonly used measure of Oral Health-Related Quality of Life (OHRQoL) and its validity and reliability have been tested among children/adolescents aged 11 to 14 years in many languages and populations. This innovative study was aimed to validate the CPQ among adolescents aged 15 to 18 in the population survey of orthodontic anomalies in Lithuania.

Methods: Representative samples of adolescents aged 11-14 years $(N=307), 15-16$ years $(N=721)$ and $17-18$ years $(N=563)$ were selected from public schools of Lithuania. The CPQ including four domains, namely oral symptoms (OS), functional limitations (FL), emotional well-being (EWB), and social well-being (SWB), was used to measure OHRQoL. A self-reported malocclusion and orthodontic examinations were used to assess malocclusion.

Results: The distributions of individual items and sum scores of the CPQ and its domains did not differ significantly between 11-14, 15-16 and 1718 age groups of adolescents. Across all age groups, Cronbach's alpha for the total CPQ was approximately equal to 0.90 indicating good internal consistency reliability; the total CPQ and all domains significantly correlated with oral health, oral well-being and global life satisfaction. Discriminant validity analysis revealed that adolescents with severe malocclusion suffered a greater impact on their emotional and social well-being than those without malocclusion, however, this relationship was more engaging in group of adolescents aged 15-18 than in 11-14-year-olds. A moderate agreement between child and parental reports was found for OS and FL domains.
\end{abstract}

Conclusions: The Lithuanian version of the CPQ for measuring OHRQoL among adolescents aged 15 to 18 years seems to be as valid and reliable as for adolescents aged 11 to 14 years.

Keywords: Oral health-related quality of life, Child Perceptions Questionnaire, validity, reliability, orthodontics, adolescents, Lithuania

\section{Introduction}

Oral health-related quality of life (OHRQoL) is a holistic concept which determines the subjective functional and psycho-social impacts of oral disease on overall well-being.[1-3] Measuring OHRQoL provides essential information when making clinical decisions for individuals and helping public health actions and policies to uncover the needs of the society in prevention and treatment of oral disorders. [3-5] Hence, OHRQoL has been widely studied over the past two decades and many tools have been developed, but mostly for adults. $[6,7]$

Recently, increasing attention has been also paid to OHRQoL in children and adolescents. The OHRQoL instruments designed to assess the impact of oral conditions on the daily lives of children and adolescents have been developed ranging from measurement of patient-reported oral functional and psychosocial problems to subjective well-being relating to oral health. Systematic reviews $[8,9]$ identified at least three validated instruments to measure OHRQoL in children and adolescents: Child Oral Impact of Daily
Performances index,[10] Child Oral Health Impact Profile,[11] and Child Perceptions Questionnaire.[12]

The most commonly used OHRQoL questionnaire is the Child Perceptions Questionnaire (CPQ). It was developed by Jokovic et al. [12] as the $\mathrm{CPQ}_{11-14}$ for children aged from 11 to 14 and was originally validated in children with caries, malocclusion and craniofacial anomalies.[12] In terms of cognitive development, age specific versions of this tool have been produced.[13] The CPQ does also have an analogous Parental CPQ which can be used as a proxy to Child CPQ.[14] The original item pool of the CPQ consists of 37 items, but the authors have also determined the psychometric properties of its shortened forms.[15] All variations of the CPQ evaluate the frequency of oral and orofacial impacts on children OHRQoL at symptomatic, functional, emotional and social levels whereas other questionnaires focus on severity of oral impacts. To date, the CPQ has been translated, validated and adapted to suit a number of languages and socio-cultural contexts demonstrating its applicability and perfect psychometric properties on numerous clinical and epidemiological occasions.[16-22] 
OHRQoL research among children and adolescent in Lithuania is still nascent and no measures have been validated to date. Given the positive CPQ properties and its high applicability for both clinical assessments and large-scale population studies we have chosen this instrument for measure of OHRQoL in our research. It was also considered that the original long form (37 items) of this instrument is more sensitive to changes in oral conditions rather than its short forms, [15] hence, the original questionnaire was taken in focus. As it is well known that every time as the measurement scale is used in a new context or with a different population group, it is necessary to test its psychometric properties.[23] Therefore, our recent study, like most other similar studies, has been focused on adaptation and validation of the $\mathrm{CPQ}_{11-14}$ in Lithuanian adolescents aged 11-14 years. A detailed examination of psychometric characteristics including factorial analysis of the Lithuanian version of CPQ with a modified item of the oral pain showed that the instrument is valid to be used in further studies for measuring OHRQoL among 11-14-year-old adolescents in Lithuania (Kavaliauskienè A, Šidlauskas A, Zaborskis A., 2018. Manuscript under review).

This study is a part of a large research project aimed to examine extend of orthodontic anomalies and OHRQoL among children and adolescents aged from 11 to 18 years in Lithuania. Hence, there was a problem to choose an appropriate instrument to measure OHRQoL among adolescents up to the ages of 18 . We hypothesized that the association between severity of oral disorders and OHRQoL in older adolescent samples (e.g. in 15-16- or 17-18-year-olds) is possibly more evident than in sample of adolescent aged 11-14 years. Therefore, the CPQ instrument to measure OHRQoL among older adolescents could be as much valid as it was valid for adolescents aged 11-14 years. Only a few relevant studies were conducted among adolescents over the age of 14 but none in population older than 16 years of age [24-27].

As a consequence, the aim of the present study was to validate the CPQ among adolescents aged from 15 to 18 in the population survey of orthodontic anomalies in Lithuania.

\section{Methods and Material}

The study followed a cross-sectional design and was a part of a larger research project aimed to examine OHRQoL among children and adolescents in Lithuania. It was conformed to the principles outlined in the Declaration of Helsinki. Ethical approval for the study was granted by the Kaunas Regional Biomedical Research Ethics Committee (reference number BE-2-27) and was in line with local practice for school survey distribution. Written informed consent for child's participation in the study was sought from both parents prior to his/her participation in the research.

Target population was adolescents aged 11-18 years. The sample being studied was made up of students from 26 randomly selected public schools using random cluster (school, class) sampling and included approximately 2000 students. School authorities were contacted by researchers and informed about all aspects of the study. Parents were then asked to provide permission for their child to participate in the study.

Data was collected using both questionnaires and dental examinations. The self-completed questionnaires for students were administrated in school classrooms before dental examination by the classroom teaching staff to ensure a familiar and consistent environment. Confidentiality and anonymity of respondents was ensured. A total of 1591 students ( $80 \%$ of initial sample and $94 \%$ of those who had parents' permission) presented correctly completed questionnaires. Those parents who gave consents were also asked to complete a self-report questionnaire about child's oral health and wellbeing. The number of correctly completed parents' questionnaires was 1365 (67\% of invited parents).

The orthodontic examination was a part of the dental examination. It was carried out in randomly selected 20 of 26 schools. Students' examination was performed according to the methodology of oral status evaluation recommended by the WHO under standardized conditions in the school's medical offices using portable equipment for dental examination [28]. The orthodontic examination of all students was undertaken by one orthodontist (A.K.) who was trained and tested in reliability of accessing orthodontic status (U.K. Cardiff University School of Dentistry, 2012) and her assistant.

In the end, 911 students participated both in the questionnaire and dental surveys, and 1365 parents provided their completed questionnaires to students who participated in the questionnaire survey. The size of studied sample was adequate to the minimum calculated as necessary $(N=969)$. Figure 1 presents flow diagram of data collection and also illustrates the sample structure by age of adolescents.

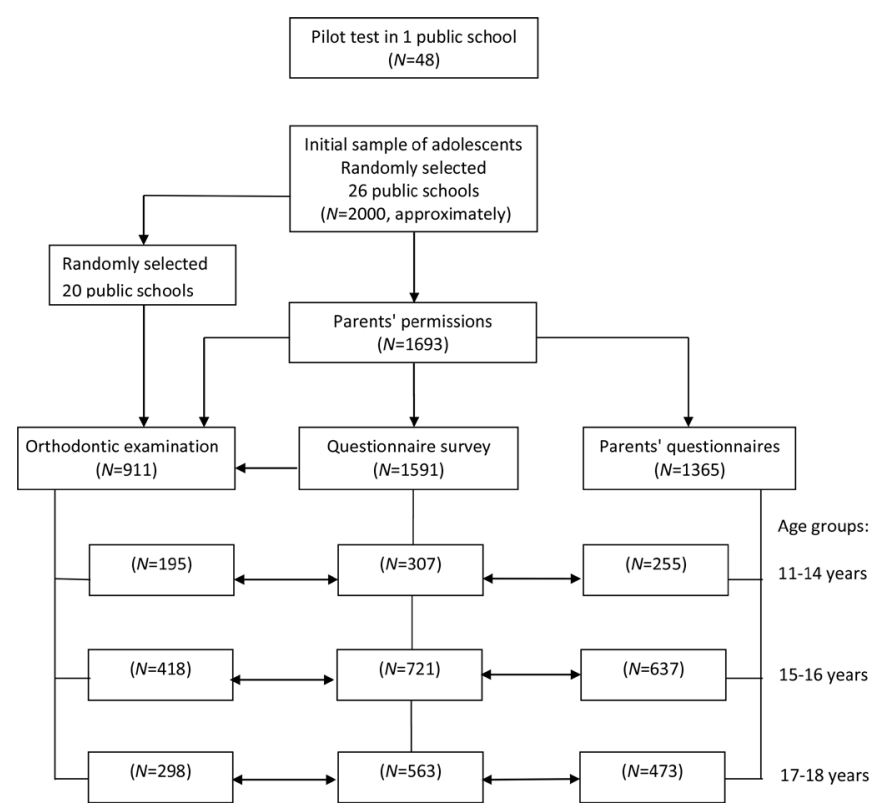

Figure 1. Flow-diagram of the data collection process and distribution of participants in three age groups.

Before the main study, a pilot test was carried out with a sample $(N=48)$ of students in one school. It confirmed the feasibility of the methodology with only minor modification of questionnaire wording and confirmed the organization of data collection procedures.

The originally created self-reported questionnaires for students and parents consisted of items assessing oral health and OHRQoL as well as demographic and social aspects of adolescent health. 
The Lithuanian version of the of $\mathrm{CPQ}_{11-14}$, cross-culturally adapted and validated for Lithuanian adolescents aged 11-14 years (Kavaliauskienè A, Šidlauskas A, Zaborskis A., 2018. Manuscript under review), was employed to evaluate the impact of oral conditions on the quality of life of adolescents of all ages. This questionnaire, as originally proposed by Jokovic et al.,[12] was a 37-item scale consisting of four health domains (subscales), namely oral symptoms (OS, 6 items), functional limitations (FL, 9 items), emotional wellbeing (EWB, 9 items), and social well-being (SWB, 13 items). The items of the OS and FL domains were also included into the parents' questionnaire in order to test their agreement with their child's report on his oral health troubles (the domains EWB and SWB were not included into the parents' questionnaire as parents may not know so well the feelings of their children). The items are scored on a 5-point Likert scale ranging from 0 ("never") to 4 ("every day or almost every day"). In the analysis, the scores for each item were added together to obtain a sum scores of each sub-scale as well as the total CPQ scale. Then, the sum scores were standardized to a percentage score scale of $0-100 \%$ by dividing the sum score by the maximum score and multiplying by 100 . Note that higher sum/percentage scores refer to worse OHRQoL.

The students were also asked to rate their oral health and the extent to which it affected their well-being. For each of these dimensions five sub-items were worded in the following way: "How would you describe health status of the following oral parts: - teeth; - lips; - gum; - oral mucosa; - jaws or joints?" and "Over the last three months, how much your overall life was affected by the conditions of the following oral parts: - teeth; - lips; - gum; - oral mucosa; - jaws or joints?" The responses were scored in the following way: with regard to an oral health rating: $0=$ excellent, $1=$ very good, $2=$ good, $3=$ fair and $4=$ poor; with regard to well-being: $0=$ not at all, $1=$ very little, $2=$ somewhat, $3=a$ lot and $4=$ very much. The final score computed the maximal score on all the sub-items of each dimension.

The global life satisfaction, or well-being, of adolescents was rated using the measurement technique from the Health Behaviour in School-aged Children (HBSC) study [28]. Children were asked to take a look at the drawn ladder, with steps numbered from zero (" 0 ") at the bottom to ten ("10") at the top, with the instruction to suppose the top of the ladder represented the best possible life, and the bottom of the ladder represented the worst possible life. Then they were asked to indicate the step of the ladder at which they would place their lives at present. Thus, the response was scored from 0 to 10 .

In the questionnaires, the respondents were asked to rate their malocclusion experience by answering to the question, whether they had ever noticed that their teeth were irregularly grew/situated or they had malocclusion. The answer categories were: 1-yes, I noticed just myself; 2-yes, this was confirmed by dentist; 3 - no, I don't have such disorders. In analyses, the first two categories were combined, thus, two sub-groups of respondents, correspondingly 'not healthy' and 'healthy', were selected.

During the orthodontic examination, the Index of Orthodontic Treatment Need (IOTN) and the Index of Complexity, Outcome and Need (ICON) were recorded according to the methodology by
Richmond (2008).[30] The IOTN measure categorizes the severity of malocclusion based on the relative effect of the various deviant occlusal traits on the longevity of the dentition. The five grades were outlined. Grade 1 recorded small deviations from normal and was categorized as 'no need of orthodontic treatment'. The deviant occlusal anomalies become more severe in Grades 2, 3 and 4, while grade 5 represented the most severe malocclusion (e.g., impacted teeth, large overjet greater than $9 \mathrm{~mm}$, defects of cleft lip and palate) and was categorized as 'very great need of orthodontic treatment'. Grade 4 and 5 were regarded as clinical need for treatment. The another indicator of malocclusion, ICON, is based on five components, which are incorporated into calculation of the ICON value by a following regression equation: $\mathrm{ICON}=($ Aesthetic assessment $\times 7)+($ Upper arch crowding/Upper spacing $\times 5)+($ Crossbite $\times 5)+($ Incisor open bite/ Incisor overbite $\times 4)+($ Bucal segment antero-posterior $\times 3)$. An ICON value of $>43$ corresponds to severe malocclusion with a fundamental treatment need [30].

The statistical analysis was performed using the Complex Samples module of the SPSS statistical package (version 21; IBM SPSS Inc., Chicago, IL, 2012) which adjust for the complex cluster-stratified sampling method (schools, classes).[31] All reported $p$ values were from two-sided statistical tests and $p$ values $\leq 0.05$ were considered statistically significant.

Missing data of the CPQ items was replaced with the personal mean if a health domain had not more than half blank items, otherwise the record was excluded from analysis. The distributions of the sum score of the CPQ and its domains were examined and found not to be normally distributed. Therefore, median and Interquartile Range (IQR) were used to describe these distributions and to test the null hypothesis that there is no difference in the CPQ scores between the malocclusion and non-malocclusion groups. Due to the same reasons, binary associations between variables were evaluated with nonparametric Spearman correlation coefficient.

A set of test was used for examination of psychometric properties of the CPQ.[32-34] The Cronbach's alpha was used as measure of internal consistency reliability of the total instrument and its domains. Their values $\geq 0.70$ were considered acceptable.[33, 34] Furthermore, other tests of internal reliability (inter-item and itemtotal correlations) were also investigated. Construct validity of the instrument was tested using Spearman correlation coefficient to assess the association between the scores of total scale as well as its domains and the respondents' rating of their oral health, oral health related well-being, and global life satisfaction. Discriminant validity was tested by comparing the medians of scores between groups defined by malocclusion traits.

Test-retest reliability test of the instrument was not employed. Instead of this, we assessed agreement between children's and their parents' answers to the same questions of the OS and FL domains. The association between child and parental sum scores was assessed by Spearman correlation coefficient, and agreement between two groups of raters was evaluated by the Intra-class Correlation Coefficient (ICC) using two way mixed consistency method and the quadratic weighted kappa.[34] The quadratic weighted kappa was used due to high range of sum scores. 


\section{Results}

In this study, the sample consisted of 1591 adolescents recruited in the questionnaire survey, among which 911 adolescents were examined by an orthodontist. Participants were divided into three groups by age: $11-14$ years ( $N=307), 15-16$ years $(N=721)$ and $17-18$ years $(N=563)$ (see Figure 1$)$. In this paper, we looked into the validity of the CPQ scale among adolescents 15-16- and 17-18-year-old, so these groups were more numerous than the reference group of 11-14-year-olds. A total of 927 (58.3\%) individuals in the sample were female. The respondents represented both the urban area (68.5\%) and rural area (31.5\%).

The response rate to the items of the CPQ varied by domains and age groups from $97.1 \%$ to $100 \%$ with the highest rate $(2.9 \%)$ of blanks in responses to the items of the SWB domain among 11-14-year-old adolescents. All unanswered questions were restored according to the accepted rules of methods.

The impacts, that is the items scored from 1 (' 1 or 2 times') to 4 ('every day or almost every day'), were reported most frequently in the OS domain ("Pain in teeth, lips, jaws or mouth" - 68.8\%; "Food stuck in or between teeth" - $62.0 \%$; "Bleeding gums" - 53.6\%; "Bad breath" $-45.2 \%$ ) and in the EWB domain ("Worried that he/she is not as good looking as others" - 38.3\%; "Worried that he/she is not as healthy as others" - 28.8\%). Comparing three age groups, there were insignificant differences in prevalence of answers to separate items.

Descriptive statistics of the total CPQ and its domains are presented in Table 1. Sum scores were found to be highly skewed and not to be normally distributed in all the health domains with a very noticeable floor effect, especially in the SWB domain. Out of the theoretical range of $0-100 \%$ of relative scores, their mean (except OS domain) and median did not exceed $20 \%$. The distributions of individual items and sum scores of the CPQ and its domains did not differ significantly between adolescents of different age groups. In all age groups, the female adolescents than the male tended to report higher scores of the CPQ (poorer OHRQoL). The significant gender difference was observed for the EWB domain (in all age groups) and for the FL domain (in 17-18-year-olds) (data not presented).

Table 1. Summary statistics of the Child Perceptions Questionnaire and its domains, by age groups

\begin{tabular}{|c|c|c|c|c|c|c|c|}
\hline \multirow{2}{*}{ Age group } & \multirow{2}{*}{$\begin{array}{c}\text { CPQ } \\
\text { Domain }\end{array}$} & \multicolumn{5}{|c|}{ Relative scores } & \multirow{2}{*}{$p$} \\
\hline & & Mean & $(95 \% \mathrm{CI})$ & Skewness & Median & (IQR) & \\
\hline $11-14$ & CPQ & 9.7 & $(8.6-10.9)$ & 1.78 & 6.3 & $(2.7-13.5)$ & 0.509 \\
\hline \multirow[t]{4}{*}{$(N=307)$} & Domain OS & 20.9 & $(19.0-22.7)$ & 1.23 & 16.7 & $(11.1-27.8)$ & 0.206 \\
\hline & Domain FL & 7.7 & $(6.4-9.1)$ & 2.10 & 3.7 & $(0-11.1)$ & 0.895 \\
\hline & Domain EWB & 12.6 & $(10.4-14.7)$ & 2.66 & 7.4 & $(0-18.5)$ & 0.129 \\
\hline & Domain SWB & 4.0 & $(2.9-5.1)$ & 4.54 & 0 & $(0-2.6)$ & 0.330 \\
\hline $15-16$ & CPQ & 9.1 & $(8.5-9.8)$ & 1.86 & 6.3 & $(2.7-12.6)$ & \\
\hline \multirow[t]{4}{*}{$(N=721)$} & Domain OS & 21.6 & $(20.4-22.8)$ & 1.02 & 16.7 & $(11.1-33.3)$ & \\
\hline & Domain FL & 7.1 & $(6.3-7.9)$ & 2.32 & 3.7 & $(0-11.1)$ & \\
\hline & Domain EWB & 11.2 & $(9.9-12.5)$ & 2.52 & 3.7 & $(0-14.8)$ & \\
\hline & Domain SWB & 3.3 & $(2.7-3.9)$ & 4.74 & 0 & $(0-2.6)$ & \\
\hline $17-18$ & CPQ & 9.3 & $(8.5-10.1)$ & 2.04 & 6.3 & $(2.7-12.6)$ & \\
\hline \multirow[t]{4}{*}{$(N=563)$} & Domain OS & 23.1 & $(21.7-24.6)$ & 0.81 & 22.2 & $(11.1-33.3)$ & \\
\hline & Domain FL & 6.9 & $(5.8-7.6)$ & 2.64 & 3.7 & $(0-7.4)$ & \\
\hline & Domain EWB & 11.9 & $(10.4-13.4)$ & 2.18 & 3.7 & $(0-14.8)$ & \\
\hline & Domain SWB & 2.9 & $(2.3-3.5)$ & 4.21 & 0 & $(0-2.56)$ & \\
\hline
\end{tabular}

CPQ: Child Perceptions Questionnaire, OS: Oral Symptoms, FL: Functional Limitations, EWB: Emotional Well-Being, SWB: Social Well-Being, CI: Confidence Interval, IQR: Range from $1^{\text {th }}$ to $3^{\text {rd }}$ quartile, $p$ : test to compare medians across age groups.

Assessments of internal consistency reliability of the CPQ and individual domains are displayed in Table 2. Cronbach's alpha for the total CPQ was approximately equal to 0.90 in all three age groups indicating good internal consistency reliability. Despite the adolescent age, the lowest values of Cronbach's alpha were observed in the OS and FL domains being acceptable value of internal consistency reliability. For the domains EWB and SWB, the coefficient ranged from 0.82 to 0.88 , indicating good internal consistency reliability in all three age groups. There was a large range of inter-item correlation and intertotal correlation in all domains, but no noticeable difference in these figures was seen comparing age groups of respondents.
Table 3 displays the correlation between the CPQ sum scores and overall ratings of oral health and well-being, as well as with global life satisfaction indicating construct validity of the instrument. Across all age groups, total CPQ and all domains were found to be significantly $(\mathrm{p}<0.01)$ and positively correlated with oral health and oral well-being. The correlations between the global life satisfaction and the domains were significant too (a negative correlation value indicates that higher life satisfaction is related to lower rating of oral problems).

Discriminant validity of the instrument was tested assessing CPQ scores in regard to the orthodontic treatment need (Table 4). 
Malocclusion traits were recorded in the orthodontic examination and were self-reported in the questionnaire survey. According to the ICON $>43$ criterion, the need for orthodontic treatment was established in $31.6 \%, 28.0 \%$ and $26.1 \%(p>0.05)$ of adolescents aged $11-14,15-16$ and $17-18$ years respectively, and, according to the IOTN $>3$ criterion, the need for orthodontic treatment was established in $29.2 \%, 33.0 \%$ and $36.6 \%$ ( $p=0.049$ ) of adolescents by corresponding age groups. Subjectively orthodontic anomalies (but not necessarily to be treated) were reported by $55.6 \%, 56.8 \%$ and $57.7 \%$ ( $p>0.05$ ) of adolescents in corresponding age groups. Across age groups, there was seen a variation in the gradient of overall CPQ and domain sum scores by malocclusion traits. Adolescents with severe malocclusion $($ ICON $>43$ or IOTN $>3$ ) suffered a greater impact on their emotional and social well-being than those without malocclusion, however, this relationship was more engaging in groups of adolescents aged 15-16 years and 17-18 years than in 11-14-year-olds. Adolescents who subjectively reported malocclusion in comparison with their 'healthy' counterparts indicated significantly greater scores for all domains in the 15-16 age group and for the OS, EWB and SWB domains in the 17-18 age group, while only for the single EWB domain in 11-14 age group.

Table 2. Internal consistency of the Child Perceptions Questionnaire and its domains, by age groups

\begin{tabular}{|c|l|c|c|c|}
\hline $\begin{array}{c}\text { Age } \\
\text { group }\end{array}$ & CPQ/Domain & IIR range & ITR range & $\begin{array}{c}\text { Cronbach's } \\
\text { alpha }\end{array}$ \\
\hline $11-14$ & CPQ & $-0.04-0.83$ & $0.17-0.59$ & 0.90 \\
$(N=307)$ & Domain OS & $0.01-0.50$ & $0.22-0.55$ & 0.66 \\
& Domain FL & $0.05-0.56$ & $0.30-0.47$ & 0.72 \\
& Domain EWB & $0.01-0.76$ & $0.18-0.67$ & 0.82 \\
& Domain SWB & $-0.01-0.83$ & $0.34-0.63$ & 0.87 \\
\hline $15-16$ & CPQ & $-0.05-0.78$ & $0.14-0.70$ & 0.90 \\
$(N=721)$ & Domain OS & $0.16-0.73$ & $0.32-0.69$ & 0.73 \\
& Domain FL & $0.00-0.57$ & $0.12-0.56$ & 0.71 \\
& Domain EWB & $0.17-0.73$ & $0.40-0.80$ & 0.88 \\
& Domain SWB & $0.02-0.78$ & $0.29-0.71$ & 0.86 \\
\hline \multirow{2}{*}{$17-18$} & CPQ & $0.01-0.76$ & $0.20-0.63$ & 0.91 \\
$(N=563)$ & Domain OS & $0.18-0.74$ & $0.28-0.70$ & 0.71 \\
& Domain FL & $0.02-0.51$ & $0.22-0.54$ & 0.71 \\
& Domain EWB & $0.05-0.72$ & $0.17-0.78$ & 0.85 \\
& Domain SWB & $0.07-0.76$ & $0.41-0.67$ & 0.86 \\
\hline
\end{tabular}

CPQ: Child Perceptions Questionnaire, OS: Oral Symptoms, FL: Functional Limitations, EWB: Emotional Well-Being, SWB: Social Well-Being, IIR: Inter-Item Correlation, ITR: Item-Total Correlation.

It was possible to compare records of 1365 parents with records of their children who independently each from other assessed items of the OS and FL domains of child OHRQoL (Table 5). Across all age groups of adolescents, positive significant correlations between parental and children assessments were observed for sum scores of both domains whereas these correlations were evaluated as a moderate level. The moderate values of kappa and ICC also confirmed agreement between child and parental reports. These results suggest on reliability of two subscales of the CPQ in respect of repeatability by two different raters.
Table 3. Spearman correlation of the Child Perceptions Questionnaire and its domains with rating of oral health, oral well-being and global life satisfaction, by age groups

\begin{tabular}{|l|l|c|c|c|}
\hline Age group & CPQ/Domain & $\begin{array}{c}\text { Oral } \\
\text { health }\end{array}$ & $\begin{array}{c}\text { Oral } \\
\text { well-being }\end{array}$ & $\begin{array}{c}\text { Global } \\
\text { life satisfaction }\end{array}$ \\
\hline $11-14$ & CPQ & $0.36^{* *}$ & $0.49^{* *}$ & $-0.33^{* *}$ \\
\hline$(N=307)$ & Domain OS & $0.33^{* *}$ & $0.48^{* *}$ & $-0.26^{* *}$ \\
\hline & Domain FL & $0.24^{* *}$ & $0.36^{* *}$ & $-0.17^{* *}$ \\
\hline & Domain EWB & $0.31^{* *}$ & $0.38^{* *}$ & $-0.32^{* *}$ \\
\hline & Domain SWB & $0.18^{* *}$ & $0.28^{* *}$ & $-0.17^{* *}$ \\
\hline $15-16$ & CPQ & $0.46^{* *}$ & $0.52^{* *}$ & $-0.33^{* *}$ \\
\hline$(N=721)$ & Domain OS & $0.36^{* *}$ & $0.49^{* *}$ & $-0.23^{* *}$ \\
\hline & Domain FL & $0.33^{* *}$ & $0.41^{* *}$ & $-0.21^{* *}$ \\
\hline & Domain EWB & $0.37^{* *}$ & $0.39^{* *}$ & $-0.29^{* *}$ \\
\hline & Domain SWB & $0.26^{* *}$ & $0.29^{* *}$ & $-0.23^{* *}$ \\
\hline $17-18$ & CPQ & $0.49^{* *}$ & $0.58^{* *}$ & $-0.27^{* *}$ \\
\hline$(N=563)$ & Domain OS & $0.44^{* *}$ & $0.58^{* *}$ & $-0.22^{* *}$ \\
\hline & Domain FL & $0.28^{* *}$ & $0.47^{* *}$ & $-0.15^{* *}$ \\
\hline & Domain EWB & $0.42^{* *}$ & $0.42^{* *}$ & $-0.23^{* *}$ \\
\hline & Domain SWB & $0.28^{* *}$ & $0.34^{* *}$ & $-0.17^{* *}$ \\
\hline
\end{tabular}

CPQ: Child Perceptions Questionnaire, OS: Oral Symptoms, FL: Functional Limitations, EWB: Emotional Well-Being, SWB: Social Well-Being, ${ }^{* *} p<0.01$.

\section{Discussion}

This innovative study was aimed to validate the CPQ among adolescents aged from 15 to 18 in the population survey of orthodontic anomalies in Lithuania. As a reference age group was chosen a group of adolescents aged 11-14 years. The main findings of our study showed that the CPQ instrument is valid to adolescents aged 15-18 years as well as it is valid for adolescents aged 11-14 years.

According to the literature review, most of the OHRQoL studies has focused on 11-14-year-old adolescents rather on older teens. This fact is not surprising because OHRQoL is often the key motive for seeking orthodontic treatment and can considered the measurement for orthodontic treatment need and outcome.[35-37] It also relates to the fact that children of this age group make up the majority of orthodontic patients. During this age period, the whole body, including the jaws, develops intensively. So the orthodontic anomalies that has arisen in this age period can be successfully corrected, even it is assumed that it is not possible to complete a full course of orthodontic treatment before the premolars and second permanent molars have erupted at dental age 12 or 13 years.[38] Therefore, it increasingly recognized that more and more teenagers and young adults are seeking correction of their malocclusion, if this could not be done in early adolescence. Thus, orthodontists should be aware that such patients might expect orthodontic treatment to provide not only improved oral functioning and health but also enhancement of aesthetics, self-esteem and social life.[39]

More recently, a number of tools to measure OHRQoL has been developed and used in assessing an association between severity of malocclusion and patients' perception of their oral health status. The standard $\mathrm{CPQ}_{11-14}$ was developed to measure the OHRQoL among adolescents between the ages of 11 and 14 years in Canada 
Aistè Kavaliauskienè (2018) Validity of Lithuanian Version of the Child Perceptions Questionnaire Among Adolescents up to the Ages of 18

[12] and soon validated in many languages and cultures, including such as China,[40] India,[16] Korea,[21] Saudi Arabia,[22] and others. The questionnaire was also adapted to Lithuanian adolescents (Kavaliauskienė A, Šidlauskas A, Zaborskis A., 2018. Manuscript under review). After examination its psychometric properties, the Lithuanian version of $\mathrm{CPQ}_{11-14}$ showed good internal consistency, discriminant validity and acceptable agreement between children and parental responses to the same items. However, there are few studies in which the well-known CPQ would be used to measure OHRQoL in adolescents over the age of 14 years.[24-27] So we felt the lack of an instrument suitable for measuring OHRQoL throughout all adolescence period as the investigation of orthodontic anomalies among adolescents of Lithuania was targeted to the population aged from 11 to 18 years.

Table 4. Discriminant validity of the Child Perceptions Questionnaire and its domains for clinically recorded and self-reported malocclusion, by age groups

\begin{tabular}{|c|c|c|c|c|c|c|c|}
\hline \multirow{2}{*}{ Age group } & \multirow{2}{*}{$\begin{array}{l}\text { Dental health } \\
\text { malocclusion }\end{array}$} & \multirow{2}{*}{$\mathbf{N}$} & \multicolumn{5}{|c|}{ Median (IQR) of relative scores } \\
\hline & & & CPQ & Domain OS & Domain FL & Domain EWB & Domain SWB \\
\hline \multirow[t]{11}{*}{$11-14$} & \multicolumn{7}{|c|}{ Records from orthodontic examination: } \\
\hline & $\mathrm{ICON} \leq 43$ & 121 & $5.4(2.7-12.4)$ & $16.7(11.1-27.8)$ & $3.7(0-7.4)$ & $3.7(0-16.7)$ & $0(0-2.6)$ \\
\hline & $\mathrm{ICON}>43$ & 56 & $6.3(3.2-33.3)$ & $16.7(11.1-27.8)$ & $3.7(0-7.4)$ & $7.4(0-18.5)$ & $0(0-2.6)$ \\
\hline & $p$ & & 0.245 & 0.872 & 0.946 & 0.307 & 0.753 \\
\hline & $\mathrm{IOTN} \leq 3$ & 138 & $5.4(2.7-11.7)$ & $16.7(11.1-27.8)$ & $0(0-9.3)$ & $3.7(0-14.8)$ & $0(0-2.6)$ \\
\hline & IOTN $>4$ & 57 & $6.3(2.7-11.9)$ & $16.7(11.1-27.8)$ & $3.7(0-7.4)$ & $7.4(0-18.5)$ & $0(0-2.6)$ \\
\hline & $p$ & & 0.738 & 0.375 & 0.461 & 0.046 & 0.931 \\
\hline & \multicolumn{7}{|l|}{ Self-reported malocclusion: } \\
\hline & 'healthy' & 136 & $5.4(2.7-9.9)$ & $16.7(5.6-27.8)$ & $3.7(0-10.2)$ & $3.7(0-11.1)$ & $0(0-2.6)$ \\
\hline & 'not healthy' & 170 & $8.1(5.6-27.8)$ & $22.2(11.1-33.3)$ & $3.7(0-14.8)$ & $9.3(0-22.2)$ & $0(0-5.1)$ \\
\hline & $p$ & & $<0.001$ & 0.009 & 0.119 & $<0.001$ & 0.076 \\
\hline \multirow[t]{11}{*}{$15-16$} & \multicolumn{7}{|c|}{ Records from orthodontic examination: } \\
\hline & $\mathrm{ICON} \leq 43$ & 293 & $5.4(2.7-12.6)$ & $16.7(11.1-27.8)$ & $3.7(0-11.1)$ & $3.7(0-14.8)$ & $0(0-2.6)$ \\
\hline & $\mathrm{ICON}>43$ & 114 & $8.1(3.6-16.2)$ & $22.2(11.1-33.3)$ & $3.7(0-14.8)$ & $7.4(0-19.4)$ & $2.6(0-5.1)$ \\
\hline & $p$ & & 0.011 & 0.240 & 0.290 & 0.082 & 0.013 \\
\hline & IOTN $\leq 3$ & 280 & $5.4(2.7-13.5)$ & $16.7(11.1-27.8)$ & $3.7(0-11.1)$ & $3.7(0-14.8)$ & $0(0-2.6)$ \\
\hline & IOTN $>4$ & 138 & $6.3(2.7-13.7)$ & $19.4(11.1-33.3)$ & $3.7(0-11.1)$ & $7.4(3.7-34.3)$ & $2.6(0-5.1)$ \\
\hline & $p$ & & 0.463 & 0.250 & 0.720 & 0.038 & 0.039 \\
\hline & \multicolumn{7}{|l|}{ Self-reported malocclusion: } \\
\hline & 'healthy' & 311 & $4.5(1.8-9.0)$ & $16.7(5.6-27.8)$ & $3.7(0-7.4)$ & $0(0-7.4)$ & $0(0-2.6)$ \\
\hline & 'not healthy' & 409 & $7.2(3.6-15.3)$ & $22.2(11.1-33.3)$ & $3.7(0-11.1)$ & $7.4(0-18.5)$ & $2.6(0-5.1)$ \\
\hline & $p$ & & $<0.001$ & $<0.001$ & 0.048 & $<0.001$ & 0.001 \\
\hline \multirow[t]{11}{*}{$17-18$} & \multicolumn{7}{|c|}{ Records from orthodontic examination: } \\
\hline & $\mathrm{ICON} \leq 43$ & 210 & $6.3(2.7-10.8)$ & $16.7(11.1-33.3)$ & $3.7(0-8.3)$ & $3.7(0-11.1)$ & $0(0-2.6)$ \\
\hline & $\mathrm{ICON}>43$ & 74 & $9.0(5.2-18.5)$ & $22.2(11.1-38.9)$ & $3.7(0-11.1)$ & $14.8(3.7-34.3)$ & $2.6(0-5.1)$ \\
\hline & $p$ & & 0.018 & 0.499 & 0.910 & $<0.001$ & 0.045 \\
\hline & IOTN $\leq 3$ & 189 & $6.3(2.7-10.8)$ & $16.7(11.1-27.8)$ & $3.7(0-7.4)$ & $3.7(0-11.1)$ & $0(0-2.6)$ \\
\hline & IOTN $>4$ & 109 & $9.0(5.4-17.1)$ & $22.2(11.1-38.9)$ & $3.7(0-11.1)$ & $11.1(0-25.9)$ & $2.6(0-5.1)$ \\
\hline & $p$ & & 0.030 & 0.095 & 0.260 & $<0.001$ & 0.024 \\
\hline & \multicolumn{7}{|l|}{ Self-reported malocclusion: } \\
\hline & 'healthy' & 237 & $4.5(1.8-9.9)$ & $16.7(8.3-27.8)$ & $0(0-7.4)$ & $0(0-7.4)$ & $0(0-0)$ \\
\hline & 'not healthy' & 323 & $8.1(3.6-14.4)$ & $22.2(11.1-38.9)$ & $3.7(0-11.1)$ & $7.4(0-22.2)$ & $2.6(0-2.6)$ \\
\hline & $p$ & & $<0.001$ & 0.011 & 0.096 & $<0.001$ & 0.007 \\
\hline
\end{tabular}

CPQ: Child Perceptions Questionnaire, OS: Oral Symptoms, FL: Functional Limitations, EWB: Emotional Well-Being, SWB: Social Well-Being, IQR: Range from $1^{\text {th }}$ to $3^{\text {rd }}$ quartile, $p$ : Test to compare medians across groups (significant values are in bold). 
Table 5. Agreement between child and parental reports about oral symptoms and functional limitations

\begin{tabular}{|c|c|c|c|c|c|}
\hline $\begin{array}{c}\text { Age } \\
\text { groups }\end{array}$ & Domain & $\begin{array}{c}\text { Number of } \\
\text { compared } \\
\text { pairs }\end{array}$ & $\begin{array}{c}\text { Spearman } \\
\text { correlation } \\
\text { coefficient }\end{array}$ & $\begin{array}{c}\text { Quadratic } \\
\text { weighted } \\
\text { kappa }\end{array}$ & $\begin{array}{c}\text { Intraclass } \\
\text { correlation } \\
\text { coefficient } \\
\mathbf{9 5 \%} \text { CI) }\end{array}$ \\
\hline $11-14$ & Domain OS & 255 & $0.42^{* *}$ & $0.40^{* *}$ & $\begin{array}{c}0.56 \\
(0.43-0.65)\end{array}$ \\
\hline & Domain FL & 255 & $0.31^{* * *}$ & $0.33^{* * *}$ & $\begin{array}{c}0.43 \\
(0.27-0.55)\end{array}$ \\
\hline $15-16$ & Domain OS & 630 & $0.32^{* *}$ & $0.32^{* * *}$ & $\begin{array}{c}0.53 \\
(0.46-0.60)\end{array}$ \\
\hline $17-18$ & Domain OS & 469 & $0.39^{* *}$ & $0.32^{* * *}$ & $\begin{array}{c}0.58 \\
(0.51-0.64)\end{array}$ \\
\hline & Domain FL & 637 & $0.34^{* *}$ & $0.40^{* *}$ & $0.63)$ \\
\hline & Domain FL & 473 & $0.34^{* *}$ & $0.38^{* * *}$ & $\begin{array}{c}0.56 \\
(0.47-0.63)\end{array}$ \\
\hline
\end{tabular}

OS: Oral Symptoms, FL: Functional Limitations, CI: Confidence Interval, "” $\mathrm{p}<0.01$.

Adolescence is marked as a transitional period of rapid developmental changes and often perceived as a time of changing trajectories and health across the life course.[29, 41] It is reasonable that adolescents of the older stage are very different from those of the younger age stage. Older teen like young adults are capable of abstract thinking, reasoning about the past events and relating them with good or bad consequences in health.[41] Based on this assumption, we hypothesised that the CPQ instrument to measure OHRQoL among 15-18-year-old adolescents could be as much valid as it was valid for adolescents aged 11-14 years. The hypothesis was confirmed by all tests traditionally employed in questionnaire validation procedures.

Initially, it was found that the distribution of CPQ sum scores and its ratio between males and females did not differ significantly across age groups of adolescents. This may suggest that the impact of malocclusion over all adolescence does not decrease as age increases. However, our study was limited to adolescents up to 18 years, while other studies among adolescents and young adults demonstrated a negative association between age and impact on quality of life due to malocclusion.[42] Exploring gender differences, regardless of age, girls were found to be more emotionally concerned with their teeth aesthetic or, alternatively, boys may be less self-conscious about their appearance. Similar findings were reported by Peres et al.[43] who found females adolescents having greater dissatisfaction with their dental appearance (Peres et al., 2008) but in the other studies the gender difference was not established significant.[44]

Next, a good internal consistency reliability of the total CPQ with Cronbach's alpha equal to 0.90 was established in both 15-16 and 1718 age groups and was as high as in the 11-14 age group presented in our study or reported by other authors. [12] Despite the adolescent age, the alpha coefficient for the EBW and SWB domains was also greater than 0.80 . Similarly to the other CPQ validation studies, $[16,17]$ the lowest values of Cronbach's alpha were observed for the OS and FL domains. Many methodologists[33, 34] recommend a minimum alpha coefficient between 0.65 and 0.8 (or higher in many cases), thus the obtained values that varied from 0.66 to 0.73 could be considered acceptable for these domains in all age groups.

The correlation coefficients in the construct validity analysis were significant in all age groups. So construct validity of the questionnaire in survey of older adolescents was in any case as high as that found among the youngest adolescents. Compared with other studies,[17, 20 ] which considered the $C P Q$ valid for the population being assessed, the correlations between the respondents' global rating of oral health and well-being and the CPQ sum scores outlined in our study were higher in many cases. The construct validity of the questionnaire for all age groups was also confirmed by the significant relationship between CPQ of sum scores and the adolescent's global life satisfaction that is an essential dimension of young people well-being. [45] The relationship indicated that adolescents, regardless of their age, were more likely to report lower global life satisfaction when they felt any oral health-related complaints.

A discriminant validity of the CPQ was examined comparing the distribution of the CPQ scores between groups of adolescents with regard to their subjectively perceived and objectively measured orthodontic status. We found that malocclusion experience has a negative impact on the adolescents' perceptions but its strength (difference in the CPQ distribution) differed by the method of definition of severity of malocclusion and the age of adolescents. Adolescents who reported malocclusion complaints themselves (were 'not healthy' in respect to orthodontic status) were more likely to provide greater perceptions of oral health-related problems than adolescents with clinically defined need for orthodontic treatment. This finding shows that a malocclusion can be perceived differently by the affected person, and a person's degree of awareness of their malocclusion might not be related to its severity.[42] The findings of the study also suggest that young adolescents when evaluating their malocclusion by orthodontist mainly suffer emotional problems, as their OHRQoL might not be related so much with severity of malocclusion. Previous studies examining the impact of malocclusion on children (young adolescents) oral health-related perceptions have been also equivocal. Systematic reviews of literature on this issue reported studies that claimed evidence for a clear inverse association of malocclusion with OHRQoL.[46-48] At the same time, they reported studies with no clear relationship indicating that the strength of the association differed depending on the age of studied sample and cultural environment. In part, our findings confirmed this suggestion indicating that in older adolescents clinically defined need for orthodontic treatment may have a significant effect on perceived OHRQoL in more domains. Therefore, in respect of discriminant validity, the CPQ had no disadvantages both in the younger and older adolescents groups.

Finally, test-retest reliability of the CPQ instrument was not assessed due to organizational and logical reasons. With regard to organizational reasons, a retest appeared problematic as organizing another dental examination session at all of the schools participating in our study would have a complex endeavour. With the respect to logical reasons, a retest of the same students was replaced with an alternative analysis that included comparison of children's and their parents' answers to the same questions of the OS and FL sub-scales. Such comparison was not performed for the EWB and SWB subscales, because some parents may have limited knowledge about their children's OHRQoL, particularly the impact on social and emotional well-being.[49]. As in other similar studies in this field,[49-51] 
findings of the present study confirmed an agreement between child and parental reports suggesting on reliability of the PCQ in respect of its repeatability by two different raters.

As an advantage of this study may be the fact that data were collected in cross-sectional population survey of representative adolescents'sample but not within sample of patients attending dental treatment as in several studies.[12, 24,52] The adolescents completed their questionnaires at school anonymously without any influence of their parents' and dentist's opinion, thus, adolescents could express their own feelings towards their QoL. That was an important condition comparing children's and their parent responses, as well as their perceptions and orthodontic measures. This is the first study on OHRQoL among adolescents ever to be carried in Lithuania.

In terms of the limitations of our study, we conducted oral examination with respect to orthodontic disorders without assessing of dental cariousness and periodontal conditions that would have a considerable impact on OHRQoL in adolescence.[53-55] The sample was not also homogenous with respect to previously conducted orthodontic treatment. So, the possible confounding effects of these conditions on the participants' OHRQoL were not considered in the analysis. Another limitation of the research is that we worked on the "long form" (37 items) of the original $\mathrm{CPQ}_{11-14}$ together with other scales, including such as eating behaviour and self esteem. Our experience from the HBSC study [29] showed that an increase of number of items in the questionnaire may affect respondent's accuracy providing inaccurate answers, which may, consequently, reduce reliability of the tested scale. Finally, test-retest reliability of the CPQ instrument was replaced with an alternative analysis that included comparison of children's and their parents' responses to the same questions of the OS and FL domains. This approach is not free from limitations, especially in relation to its accuracy because children and parents may not share the same views about illness and health.[56]

\section{Conclusions}

The Lithuanian version of the CPQ showed good internal consistency and construct and discriminant validity in all age groups of adolescents, consequently, it seems to be a valid instrument for measuring OHRQoL among adolescents aged 15 to 18 years as well as among adolescent aged 11 to 14 years.

\section{Acknowledgements}

The authors would like to thank all reviewers for their thoughtful comments in the manuscript. A gratitude is also expressed to the schoolchildren and their parents for their participation in this study as well as to the teachers for their help during fieldwork.

\section{Competing interests}

The authors declare that they have no competing interests.

\section{Funding}

This study was funded by the Lithuanian University of Health Sciences.

$\begin{array}{ll}\text { Abbreviations } \\ \text { CI } & \text { Confidence Interval } \\ \text { CPQ } & \text { Child Perceptions Questionnaire } \\ \text { DHC } & \text { Dental Health Component } \\ \text { EWB } & \text { Emotional Well-being } \\ \text { FL } & \text { Functional Limitations } \\ \text { HBSC } & \text { Health Behaviours in School-aged Children } \\ \text { ICC } & \text { Intraclass Correlation Coefficient } \\ \text { ICON } & \text { Index of Complexity Outcome and Need } \\ \text { IIR } & \text { Inter-Item Correlation } \\ \text { IOTN } & \text { Index of Orthodontic Treatment Need } \\ \text { IQR } & \text { Interquartile Range } \\ \text { ITR } & \text { Item-Total Correlation } \\ \text { OHRQoL } & \text { Oral Health-Related Quality of Life } \\ \text { OS } & \text { Oral Symptoms } \\ \text { SD } & \text { Standard Deviation } \\ \text { SWB } & \text { Social Well-being }\end{array}$

\section{References}

1. Inglehart MR, Bagramian RA (2002) (Eds.) Oral health-related quality of life. Chicago: Quintessence Publishing Co Inc [Crossref]

2. Sischo L, Broder HL (2011) Oral health-related quality of life: what, why, how, and future implications. J Dent Res 90(11): 1264-70. [Crossref]

3. Bennadi D, Reddy CV (2013) Oral health related quality of life. J Int Soc Prev Community Dent 3(1): 1-6. [Crossref]

4. Cunningham SJ, O'Brien C. Quality of life and orthodontics. Semin Orthod 2007;13,96-103.

5. Gherunpong S, Sheiham A, Tsakos G ( 2006) A sociodental approach to assessing children's oral health needs: integrating an oral health-related quality of life (OHRQoL) measure into oral health service planning. Bull World Health Organ 84: 36-42. [Crossref]

6. Murray Thomson W (2014) Epidemiology of oral health conditions in older people. Gerodontology 31 Supp1 1: 9-16. [Crossref]

7. Lu HX, Wong MC, Lo EC, McGrath C (2015) Oral health related quality of life among young adults. Appl Res Qual Life 10(1): 37-47.

8. Genderson MW, Sischo L, Markowitz K, Fine D (2013). An overview of children's oral health-related quality of life assessment: from scale development to measuring outcomes. Caries Res 47 Suppl 1: 13-21. [Crossref]

9. Gilchrist F, Rodd H, Deery C, Marshman Z (2014) Assessment of the quality of measures of child oral health-related quality of life. BMC Oral Health 2014;14: 40. [Crossref]

10. Gherunpong S, Tsakos G, Sheiham A (2004) Developing and evaluating an oral health-related quality of life index for children; the CHILD-OIDP. Community Dent Health 21: 161-9.[Crossref]

11. Broder HL, Wilson-Genderson M (2007) Reliability and convergent and discriminant validity of the Child Oral Health Impact Profile (COHIP Child's version). Community Dent Oral Epidemiol 35 Suppl 1: 20-31. [Crossref]

12. Jokovic A, Locker D, Stephens M, Kenny D (2002) Validity and reliability of a questionnaire for measuring child oral-health-related quality of life. J Dent Res 81 : 459-63. [Crossref]

13. Jokovic A, Locker D, Tompson B, Guyatt G (2004) Questionnaire for measuring oral health-related quality of life in eight- to ten-year-old children. Pediatr Dent 26: 512-8. [Crossref]

14. Jokovic A, Locker D, Stephens M, Kenny D (2003) Measuring parental perceptions of child oral health-related quality of life. J Public Health Dent 63: 67-72.[Crossref]

15. Jokovic A, Locker D, Guyatt G (2006) Short forms of the Child Perceptions Questionnaire for 11-14-year-old children $\left(\mathrm{CPQ}_{11-14}\right)$ : Development and initial evaluation. Health Qual Life Outcomes 4: 4. [Crossref] 
16. Kumar S, Kroon J, Lalloo R, Johnson NW (2016) Psychometric Properties of Translation of the Child Perception Questionnaire $\left(\mathrm{CPQ}_{11-14}\right)$ in Telugu Speaking Indian Children. PLoS One 11(3): e0149181.[Crossref]

17. Goursand D, Paiva SM, Zarzar PM, Ramos-Jorge ML (2008) Cross-cultural adaptation of the Child Perceptions Questionnaire 11-14 $\left(\mathrm{CPQ}_{11-14}\right)$ for the Brazilian Portuguese language. Health Qual Life Outcomes 6: 2. [Crossref]

18. Gururatana O, Baker S, Robinson PG (2011) Psychometric properties of long and short forms of the Child Perceptions Questionnaire (CPQ11-14) in a Thai population. Community Dent Health 28(3): 232-7. [Crossref]

19. Bekes K, John MT, Zyriax R, Schaller HG (2012) The German version of the Child Perceptions Questionnaire (CPQ-G11-14): translation process, reliability, and validity in the general population. Clin Oral Investig 16(1): 165-71. [Crossref]

20. Olivieri A, Ferro R, Benacchio L, Besostri A (2013) Validity of Italian version of the Child Perceptions Questionnaire (CPQ11-14). BMC Oral Health 13: 55. [Crossref]

21. Shin HS, Han DH, Shin MS, Lee HJ (2015) Korean version of child perceptions questionnaire and dental caries among Korean children. PLoS One 10(2): e0116011. [Crossref]

22. Brown A, Al-Khayal Z (2006) Validity and reliability of the Arabic translation of the child oral-health-related quality of life questionnaire (CPQ11-14) in Saudi Arabia. Int J Paediatr Dent 16(6): 405-11.[Crossref]

23. Streiner D, Norman G (2000) Health Measurement Scales. A practical guide to their development and use. 2nd edition. New York, Oxford University Press.

24. De Baets E, Lambrechts H, Lemiere J, Diya L (2012) Impact of self-esteem on the relationship between orthodontic treatment need and oral health-related quality of life in 11- to 16-year-old children. Eur J Orthod 34: 731-7. [Crossref]

25. Paula JS, Cruz JND, Ramires TG, Ortega EMM (2017) Longitudinal impact of clinical and socioenvironmental variables on oral health-related quality of life in adolescents. Brazilian Oral Res 31,e70. doi: 10.1590/1807-3107BOR-2017. vol31.0070 [Crossref]

26. Ahuja V (2013) Oral health related quality of life among Iowa adolescents. Master thesis. Iowa City: The University of Iowa.

27. Sun L, Wong HM, McGrath CPJ (2018) The factors that influence oral healthrelated quality of life in 15-year-old children. Health Qual Life Outcomes 16,19. [Crossref]

28. WHO. Oral Health Surveys: Basic Methods. 5th ed. Geneva: World Health Organization. 2013.

29. Inchley J, Currie D, Young T, Samdal O, et al. (Eds.) Growing up unequal: gender and socioeconomic differences in young people's health and well-being. Health Behaviour in School-aged Children (HBSC) study: International report from the 2013/2014 survey. Copenhagen: World Health Organization Regional Office for Europe, 2016.

30. Richmond S (2008) Evaluating effective orthodontic care. $1^{\text {st }}$ ed. Cardiff Medicentre. First Numerics Ltd

31. IBM Corp. IBM SPSS Complex Samples 21. Armonk, NY, USA: IBM Corp, 2012.

32. Streiner D, Norman G. Health Measurement Scales. A practical guide to their development and use. 2nd edition. New York, Oxford University Press, 2000

33. Pakalniškienè V. Tyrimo ir ịvertinimo priemoniu patikimumo ir validumo nustatymas. Metodine priemone. (Evaluation of validity and reliability for examination and assessment tools.) Vilnius: Vilniaus universiteto leidykla, 2012 (in Lithuanian).

34. Aldridge V. Reliability Assessment Using SPSS. University of York, Centre for Applied Statistics Courses, UCL Institute of Child Health, 2015. Available: http: // www.spssusers.co.uk/Events/2015/ALDRIDGE2015.pdf.

35. Kiyak HA. (2008) Does orthodontic treatment affect patients' quality of life? J Dent Educ 72(8): 886-94. [Crossref]

36. Feu D, de Oliveira BH, de Oliveira Almeida MA, Kiyak HA(2010) Oral healthrelated quality of life and orthodontic treatment seeking. Am J Orthod Dentofacial Orthop 138: 152-9 [Crossref]
37. Masood M, Masood Y, Saub R, Newton JT (2014) Need of minimal important difference for oral health-related quality of life measures. J Public Health Dent 74 : 13-20. [Crossref]

38. Bennett JC (2006) Orthodontic management of uncrowded class II division 1 malocclusion in children. London, UK: Elsevier.

39. Chen M, Feng ZC, Liu X, Li ZM (2015) Impact of malocclusion on oral healthrelated quality of life in young adults. Angle Orthod 85(6): 986-91. [Crossref]

40. McGrath C, Pang HN, Lo EC, King NM (2008) Translation and evaluation of a Chinese version of the Child Oral Health-related Quality of Life measure. Int J Paediatr Dent 18: 267-74. [Crossref]

41. Sawyer SM, Afifi RA, Bearinger LH, Blakemore SJ (2012) Adolescence: A foundation for future health. The Lancet 379(9826): 1630-40. [Crossref]

42. Masood Y, Masood M, Zainul NN, Araby NB (2013) Impact of malocclusion on oral health related quality of life in young people. Health Qual Life Outcomes 11: 25. [Crossref]

43. Peres KG, Barros AJ, Anselmi L, Peres MA (2008) Does malocclusion influence the adolescent's satisfaction with appearance? A cross-sectional study nested in a Brazilian birth cohort. Community Dent Oral Epidemiol Apr;36(2): 137-43.

44. de Oliveira CM, Sheiham A (2004) Orthodontic treatment and its impact on oral health-related quality of life in Brazilian adolescents. J Orthod 31(1): 20-7; discussion 15. [Crossref]

45. Kavaliauskienè A, Šidlauskas A, Zaborskis A (2017) Association between Global Life Satisfaction and Self-Rated Oral Health Conditions among Adolescents in Lithuania. Int J Environ Res Public

46. Zhang M, McGrath C, Hagg U (2006) The impact of malocclusion and its treatment on quality of life: a literature review. Int J Paed Dent 16: 381-7. [Crossref]

47. Liu Z, McGrath C, Hägg U (2009) The impact of malocclusion/ orthodontic treatment need on the quality of life. A systematic review. Angle Orthod 2009;79: 585-91. [Crossref]

48. Kragt L, Dhamo B, Wolvius EB, Ongkosuwito EM (2016) The impact of malocclusions on oral health-related quality of life in children-a systematic review and meta-analysis. Clin Oral Investig 20(8): 1881-94. [Crossref]

49. Barbosa TS, Gavião MB (2015) Validation of the Parental-Caregiver Perceptions Questionnaire: agreement between parental and child reports. J Public Health Dent Fall 75(4): 255-64. [Crossref]

50. Barbosa TS, Gavião MB (2008) Oral health-related quality of life in children: part III. Is there agreement between parents in rating their children's oral health-related quality of life? A systematic review. Int J Dent Hyg 6(2): 108-13. [Crossref]

51. Li YJ, Gao YH, Zhang Y (2014) The impact of oral health status on the oral healthrelated quality of life (OHRQoL) of 12-year-olds from children's and parents' perspectives. Community Dent Health 31(4): 240-4. [Crossref]

52. O'Brien C, Benson PE, Marshman Z (2007) Evaluation of a quality of life measure for children with malocclusion. J Orthod 34(3): 185-93; discussion 176. [Crossref]

53. Naito M, Yuasa H, Nomura Y, Nakayama T (2006) Oral health status and healthrelated quality of life: a systematic review. J Oral Sci 48(1): 1-7. [Crossref]

54. Barbosa TS, Gavião MBD, Castelo PM, Leme MS (2016) Factors Associated with Oral Health-related Quality of Life in Children and Preadolescents: A Crosssectional Study. Oral Health Prev Dent 14(2): 137-48. [Crossref]

55. Martins MT, Sardenberg F, Bendo CB, Abreu MH (2017) Dental caries remains as the main oral condition with the greatest impact on children's quality of life. PLoS One 12(10): e0185365. doi: 10.1371/journal.pone.0185365. [Crossref]

56. Jokovic A, Locker D, Stephens M, Kenny D (2003) Measuring parental perceptions of child oral health-related quality of life. J Public Health Dent 63(2): 67-72. [Crossref]

Citation:

Aistė Kavaliauskienè, Antanas Šidlauskas and Apolinaras Zaborskis (2018) Validity of Lithuanian Version of the Child Perceptions Questionnaire Among Adolescents up to the Ages of 18. J Clin Res Med Volume 1(2): 1-9 